\title{
Synergistic effects of tacrolimus and azole antifungal compounds in fluconazole-susceptible and fluconazole-resistant Candida glabrata isolates
}

\author{
Laura Bedin Denardi ${ }^{1}$, Débora Alves Nunes Mario ${ }^{1}$, Érico Silva Loreto ${ }^{2}$, \\ Janio Morais Santurio ${ }^{2}$, Sydney Hartz Alves ${ }^{1}$ \\ ${ }^{1}$ Programa de Pós-Graduação em Ciências Farmacêuticas, Centro de Ciências da Saúde, \\ Universidade Federal de Santa Maria, Santa Maria, RS, Brasil. \\ ${ }^{2}$ Programa de Pós-Graduação em Farmacologia, Centro de Ciências da Saúde, \\ Universidade Federal de Santa Maria, Santa Maria, RS, Brasil.
}

Submitted: December 12, 2012; Approved: June 6, 2014.

\begin{abstract}
In vitro interaction between tacrolimus (FK506) and four azoles (fluconazole, ketoconazole, itraconazole and voriconazole) against thirty clinical isolates of both fluconazole susceptible and -resistant Candida glabrata were evaluated by the checkerboard microdilution method. Synergistic, indifferent or antagonism interactions were found for combinations of the antifungal agents and FK506. A larger synergistic effect was observed for the combinations of FK506 with itraconazole and voriconazole (43\%), followed by that of the combination with ketoconazole (37\%), against fluconazole-susceptible isolates. For fluconazole-resistant C. glabrata, a higher synergistic effect was obtained from FK506 combined with ketoconazole (77\%), itraconazole (73\%), voriconazole (63\%) and fluconazole $(60 \%)$. The synergisms that we observed in vitro, notably against fluconazoleresistant $C$. glabrata isolates, are promising and warrant further analysis of their applications in experimental in vivo studies.
\end{abstract}

Key words: Candida glabrata, azole resistance, FK506, combination therapy.

\section{Introduction}

In the last few decades, invasive fungal infections that are caused by Candida species have risen in parallel with the number of immunocompromised patients, such as those with AIDS, transplant recipients and cancer therapy patients (Bastert et al., 2001). Candida glabrata is currently the second most common cause of candidemia in the United States (Pfaller et al., 2007). In Brazil C. glabrata is an emerging pathogen especially in private hospitals, attributed mainly to the use of prophylactic therapy with fluconazole (Colombo et al., 2013; Pasqualotto et al., 2009). The increased number of C. glabrata systemic infections is very concerning due to the high mortality rate. C. glabrata fungemia is frequently difficult to treat due to its intrinsic or rapidly acquired resistance to azole antifungals (Pfaller et al., 2007), which has emerged in clinical isolates from immunocompromised patients (Onyewu et al., 2003).

The treatment for Candida infections that show resistance to fluconazole has been the use of other antifungal azoles such as voriconazole, posaconazole and ravuconazole and other classes of antifungal agents, such as amphotericin and echinocandins (Colombo et al., 2013; Pappas et al., 2009). However, the cross-resistance phenomenon among azoles is well-established (Pfaller et al., 2007), as well as for amphotericin (Hull et al., 2012) and echinocandins emergence of resistance has been detected when they are used for C. glabrata infection treatment (Alexander et al., 2013; Niimi et al., 2012; Pfaller et al., 2012). Combination therapy is an alternative that can be used to improve the efficacy of antimicrobial therapy for difficult-to-treat infections, either by combining different antifungals or combining antifungal and non-antifungal agents, which can decrease antimicrobial resistance (Mukherjee et al., 2005).

Send correspondence to L.B. Denardi. Programa de Pós-Graduação em Ciências Farmacêuticas, Centro de Ciências da Saúde, Universidade Federal de Santa Maria,Campus UFSM, Prédio 20, sala 4139, 97105-900 Santa Maria, RS, Brazil. E-mail: laura-denardi@hotmail.com. 
FK506 is a calcineurin inhibitor that prevents T-cell proliferation and suppresses the immune responses that are involved in transplant rejection (Blankenship and Heitman, 2005). Recent studies have shown that calcineurin inhibitors, such as cyclosporin A and FK506 have synergistic interactions when combined with azole antifungal agents, resulting in fungicidal activity (Steinbach et al., 2004). However, these antifungal activities against $C$. glabrata resistant isolates to azoles have not been evaluated. In this context, the aim of this study was to evaluated the in vitro activity of each antifungal (FLZ, KTZ, ITZ and VCR) alone and combined with FK506 against both fluconazolesusceptible and fluconazole-resistant $C$. glabrata isolates using the Clinical and Laboratory Standards Institute guidelines (CLSI, 2008) standardised broth microdilution method.

\section{Material and Methods}

\section{Microorganisms}

We studied two groups of Candida glabrata isolates. The first included thirty fluconazole-susceptible (FS) clinical isolates that were recovered from AIDS patients. The second group included thirty fluconazole-resistant isolates obtained via induction of resistance, as previously described by Fekete-Forgacs et al. (2000). Strains were categorized as susceptible, susceptible dose dependent or resistant to fluconazole according to the interpretative breakpoints of CLSI M27-A3 criteria ( $\leq 8$; 16-32; or $\geq 64 \mu \mathrm{g} / \mathrm{mL}$ respectively). All of the yeasts were identified using the commercial kit ID 32C (bioMérieux, Marcy l'Etoile, France). In addition, Candida glabrata (ATCC 2001) was used as quality control.

\section{Chemicals}

Ketoconazole (KTZ), itraconazole (ITZ) and FK506 (Janssen-Cilag Pharmaceutica, Belgium), voriconazole (VRC) (Pfizer, Inc., New York, NY) and fluconazole (FLZ) (Sigma Chemical Co., St. Louis, MO) were obtained as standard powders. A stock solution for FLZ was prepared by dissolving the powder in distilled water, and stock solutions for the other tested drugs were prepared by dissolving ITZ, KTZ and VRC in dimethyl sulphoxide and FK506 in methanol. The stock solutions were stored at $-70^{\circ} \mathrm{C}$ until use.

\section{In vitro susceptibility and drug interaction tests}

Susceptibility tests were performed according to the CLSI protocol M27-A3 microdilution technique (CLSI, 2008), and the highest concentrations used were 64.00 $\mu \mathrm{g} / \mathrm{mL}$ for FK506, $512.00 \mu \mathrm{g} / \mathrm{mL}$ for fluconazole and 32.00 $\mu \mathrm{g} / \mathrm{mL}$ for other the azoles. The interaction between FK506 and the azoles against thirty strains each of fluconazolesusceptible and -resistant $C$. glabrata was evaluated using the microdilution checkerboard method. Drug dilutions were prepared in order to obtain four times the final concentra- tions, and $50 \mu \mathrm{L}$ of each concentration of azoles was added to columns 1 to 10 and $50 \mu \mathrm{L}$ of each concentration of FK506 was added to rows A to G. The concentrations of FK506 ranged from $0.25 \mu \mathrm{g} / \mathrm{mL}$ to $32.00 \mu \mathrm{g} / \mathrm{mL}$, and the concentrations of the azole antifungals ranged from $0.03 \mu \mathrm{g} / \mathrm{mL}$ to $256.00 \mu \mathrm{g} / \mathrm{mL}$. The experiment was tested in triplicate. The fractional inhibitory concentration (FIC) was calculated for each agent by dividing the minimal inhibitory concentration (MIC) of each drug in combination by the MIC of the drug alone. The FIC values were then totalled to determine the fractional inhibitory concentration index (FICI) that resulted from the drug combinations, as the following equation: $\mathrm{FICI}=\mathrm{FIC}_{\mathrm{A}}+\mathrm{FIC}_{\mathrm{B}}=\mathrm{C}_{\mathrm{A}}{ }^{\mathrm{Comb}} / \mathrm{MIC}_{\mathrm{A}}$ Alone + $\mathrm{C}_{\mathrm{B}}{ }^{\mathrm{Comb}} / \mathrm{MIC}_{\mathrm{B}}{ }^{\text {Alone }}$, where $\mathrm{MIC}_{\mathrm{A}}$ Alone and $\mathrm{MIC}_{\mathrm{B}}{ }^{\text {Alone }}$ are the MICs of drugs $A$ and $B$ when acting alone and $C_{A}{ }^{C o m b}$ and $C_{B}$ ${ }^{\mathrm{Comb}}$ are the concentrations of drugs $\mathrm{A}$ and $\mathrm{B}$ when combined. Synergism was defined as an FICI $\leq 0.5$, indifference was defined as $1.0<\mathrm{FICI} \leq 4$, and antagonism was defined as FICI $>4$ (Johnson et al., 2004). The statistical analysis of combinations was performed using one-way ANOVA followed by post-hoc Tukey's test. The statistical analysis used to evaluate the different groups (susceptible strains vs. resistant strains) when antifungal acting alone was $\mathrm{T}$ test. In all the statistical tests, it was considered a significance level of $5 \%(\mathrm{p} \leq 0.05)$.

\section{Results}

Based on the parameters of susceptibility (MIC range, $\mathrm{MIC}_{50}, \mathrm{MIC}_{90}$ and geometric mean), as shown in Table 1, fluconazole-susceptible (FS) strains showed lower MICs to ketoconazole $(0.13-2.00 \mu \mathrm{g} / \mathrm{mL})$, itraconazole $(0.50$ $8.00 \mu \mathrm{g} / \mathrm{mL})$, voriconazole $(0.13-4.00 \mu \mathrm{g} / \mathrm{mL})$ and fluconazole (1.00-32.00 $\mu \mathrm{g} / \mathrm{mL})$ compared to fluconazole-resistant (FR) strains, which showed MIC ranges of 0.50 $16.00 \mu \mathrm{g} / \mathrm{mL}$ for ketoconazole, $1.00-16.00 \mu \mathrm{g} / \mathrm{mL}$ for itraconazole, $1.00-16.00 \mu \mathrm{g} / \mathrm{mL}$ for voriconazole and 64.00 $256.00 \mu \mathrm{g} / \mathrm{mL}$ for fluconazole.

The statistical analysis showed significant differences between the susceptibility of FS vs. FR groups for all azole antifungal ( $\mathrm{p}<0.0001$ (FLZ); $\mathrm{p}<0.0023$ (KTZ); $\mathrm{p}<0.01$ (ITZ and VCR)). Because C. glabrata fluconazole-resistant (FR) strains showed an increase in the MIC for all antifungal agents, cross-resistance appears to occur between fluconazole and the other azoles. FK506 did not show activity against FS and FR strains at the highest concentration tested. Table 2 shows the percentages of synergism, indifference and antagonism that resulted from the combinations of FK506 with ketoconazole, itraconazole, voriconazole and fluconazole against the FS and FR group.

FK506 combined with ketoconazole against the FR strains showed $77 \%$ of synergism, followed by the combinations with itraconazole $(73 \%)$, voriconazole $(63 \%)$ and fluconazole $(60 \%)$. These results showed that the percent- 
Table 1 - Susceptibility $(\mu \mathrm{g} / \mathrm{mL})$ of thirty fluconazole-susceptible (FS) and fluconazole-resistant (FR) Candida glabrata strains to fluconazole, ketoconazole, itraconazole and voriconazole.

\begin{tabular}{|c|c|c|c|c|c|}
\hline Agents & Group of isolates & Geometric mean & MIC Range & $\mathrm{MIC}_{50}$ & $\mathrm{MIC}_{90}$ \\
\hline \multirow[t]{2}{*}{ Fluconazole } & FS & 5.039 & $1.00-32.00$ & 4.00 & 32.00 \\
\hline & FR & 147.033 & $64.00-256.00$ & 128.00 & 256.00 \\
\hline \multirow[t]{2}{*}{ Ketoconazole } & FS & 0.536 & $0.13-2.00$ & 0.50 & 1.00 \\
\hline & FR & 2.579 & $0.50-16.00$ & 2.00 & 8.00 \\
\hline \multirow[t]{2}{*}{ Itraconazole } & FS & 1.203 & $0.50-8.00$ & 1.00 & 4.00 \\
\hline & FR & 3.402 & $1.00-16.00$ & 4.00 & 8.00 \\
\hline \multirow[t]{2}{*}{ Voriconazole } & FS & 0.478 & $0.13-4.00$ & 0.50 & 1.00 \\
\hline & FR & 2.639 & $1.00-16.00$ & 2.00 & 8.00 \\
\hline
\end{tabular}

$\mathrm{MIC}_{50}$ : Mean the concentration at which $50 \%$ of tested strain cannot grow.

$\mathrm{MIC}_{90}$ : Mean the concentration at which $90 \%$ of tested strain cannot grow.

Table 2 - Percentages of synergism, indifference and antagonism that resulted from the combinations of tacrolimus (FK506) with fluconazole (FLZ), ketoconazole (KTZ), itraconazole (ITZ) and voriconazole (VRC) against fluconazole-susceptible (FS) and fluconazole-resistant (FR) Candida glabrata strains.

\begin{tabular}{lcccc}
\hline Agents & $\begin{array}{c}\text { Group of } \\
\text { isolates }\end{array}$ & & Interactions (\%) & \\
& & Synergism & Indifference & Antagonism \\
\hline FLZ + FK506 & FS & 3.33 & 50.00 & 46.67 \\
& FR & 60.00 & 40.00 & 0.00 \\
KTZ + FK506 & FS & 37.00 & 63.00 & 0.00 \\
ITZ + FK506 & FR & 77.00 & 23.00 & 0.00 \\
& FS & 43.00 & 57.00 & 0.00 \\
VRC + FK506 & FR & 73.00 & 27.00 & 0.00 \\
& FS & 43.00 & 57.00 & 0.00 \\
& FR & 63.00 & 37.00 & 0.00 \\
\hline
\end{tabular}

ages for the synergistic interactions against the FR strains were significantly similar for the four azoles $(p<0.0001)$. In contrast, the FS group showed lower synergism percentages for both voriconazole and itraconazole combined with FK506 (43\%) as well as for the combination with ketoconazole (37\%); these combinations didn't differ. $(p<0.0001)$. The combination with fluconazole showed a minimal synergic interaction $(3.33 \%)$. The percentages of indifference were similar for the four combinations (approximately $56 \%$ with FS group, 38\% (FLZ and VRC) and 25\% (ITZ and KTZ) with FR group). Antagonism effects were not detected for combinations with ketoconazole, itraconazole and voriconazole, however the combination with fluconazole showed $46.67 \%$ to FS strains.

\section{Discussion}

Invasive fungal infections are a significant complication in transplant patients, and $62 \%$ to $91 \%$ of these infections are caused by Candida species. In liver transplants, the manipulation of the gastrointestinal tract can translocate this microorganism through the intestinal epithelium, resulting in the development of invasive candidiasis (Singh 2003).

FK506 is one of the most common and efficient immunosuppressants used to prevent transplant rejection (Onyewu et al., 2003). This compound inhibits calcineurin, a phosphatase protein involved in lymphocyte activation that is responsible for the synthesis of cytokines, such as interleukin-2, and is primarily involved in NFAT (nuclear factor of activated T-cells) regulation. Calcineurin is activated by an increase in cytoplasmic $\mathrm{Ca}^{2+}$, and its inhibition by immunosuppressants blocks the activation of $\mathrm{T}$ lymphocytes, which is critical for an immune response (Baksh and Burakoff, 2000).

Calcineurin governing fungal physiology, including the regulation of cell cycle progression, cation homeostasis, cell wall biosynthesis, antifungal drug resistance and virulence (Blankenship and Heitman, 2005). Immunosuppressants inhibit calcineurin function in several fungal species, including Candida albicans, Cryptococcus neoformans, and Aspergillus fumigatus, affecting essential functions in cell fungal (Bader et al., 2003).

Azole antifungals stimulate calcium influx and this activates the calcium signalling pathway, which is essential for yeast survival (Bader et al., 2003). In C. albicans, calcineurin inhibition results in greater susceptibility to azole antifungal agents (Sun et al., 2008), due to the high level of stress that is caused by influx of cations such as $\mathrm{Ca}^{2+}$ and $\mathrm{Na}^{2+}$ in the fungal cell (Blankenship and Heitman, 2005). Here, we showed that the combination of FK506 with azoles can show synergism against fluconazole-susceptible and -resistant $C$. glabrata strains.

Onyewu et al. (2003) demonstrated a synergistic effect with the combination of terbinafine and FK506 against Candida glabrata, and Sun et al. (2008) showed that the activity of azole antifungal agents against $C$. albicans can be enhanced by FK506. Cruz et al. (2002) proposed that the immunosuppressant FK506 and cyclosporin analogues can 
be effective in combination with azoles for the treatment of invasive infections that are caused by Candida spp, which is in agreement with the present study showing that calcineurin inhibition can function as an adjuvant for treating invasive Candida glabrata infections.

Novel antifungal agents, such as posaconazole and echinocandins, have also been ineffective in the treatment of candidemias that is caused by C. glabrata, and susceptibility tests have confirmed drug resistance to posaconazole in these isolates (Auberger et al., 2012). Among echinocandins, decreased in vitro susceptibility and resistance has been observed in C. glabrata strains with single $f k s 1$ or $f k s 2$ mutations, or both (Alexander et al., 2013; Niimi et al., 2012). Pfaller et al. (2012) reported a study were thereabout, $11 \%$ of $C$. glabrata fluconazole-resistant isolates were also resistant to one or more echinocandins, all of which contained an acquired mutation in $f k s 1$ or $f k s 2$.

In conclusion, we demonstrated that the rates of synergism were higher among fluconazole-resistant isolates than those observed with fluconazole-sensitive C. glabrata isolates. Our results confirm that combinations of FK506 and azole antifungal agents may be promising and warrant further studies in vivo using an experimental C. glabrata infection.

\section{Acknowledgments}

We thank the Brazilian agencies CAPES for their support. Érico Silva Loreto is the recipient of a PNPDCAPES fellowship. We have no conflicts of interest.

\section{References}

Alexander BD, Johnson MD Pfeiffer CD, Jiménez-Ortigosa C, Catania J, Booker R, Castanheira M, Messer SA, Perlin DS, Pfaller MA (2013) Increasing echinocandins resistance in Candida glabrata: Clinical failure correlates with presence or FKS mutations and elevate minimum inhibitory concentration. Clin Infect Dis 56:1724-1732.

Auberger J, Lass-Florl C, Aigner M, Clausen J, Gastl G, Nachbaur D (2012) Invasive fungal breakthrough infections, fungal colonization and emergence of resistant strains in high-risk patients receiving antifungal prophylaxis with posaconazole: real-life data from a single-centre institutional retrospective observational study. J Antimicrob Chemother 67:2268-2273.

Bader T, Bodendorfer B, Schroppel K, Morschhauser J (2003) Calcineurin is essential for virulence in Candida albicans. Infect Immun 71:5344-5354.

Baksh S, Burakoff SJ (2000) The role of calcineurin in lymphocyte activation. Semin Immunol 12:405-415.

Bard M, Sturm MA, Pierson CA, Brown S, Rogers KM, Nabinger S, Eckstein J, Barbuch R, Lees ND, Howell AS, Hazen KC (2005) Sterol uptake in Candida glabrata: Rescue of sterol auxotrophic strains. Diagn Microbiol Infect Dis 52:175-180.

Bastert J, Schaller M, Korting HC, Evans EGV (2001) Current and future approaches to antimycotic treatment in the era of resistant fungi and immunocompromised hosts. Int $\mathrm{J}$ Antimicrob Agents 17:81-91.
Blankenship JR, Heitman J (2005) Calcineurin is required for Candida albicans to survive calcium stress in serum. Infect Immun 73:5767-5774.

Clinical and Laboratory Standards Institute (2008) Reference Method for Broth Dilution Antifungal Susceptibility Testing of Yeasts; Approved Standard. M27-A3. CLSI, Wayne.

Colombo AL, Guimarães T, Camargo LFA, Richtman R, Queiróz-Telles F, Salles MJC da Cunha CA, Yasuda MAS, Moretti ML, Nucci M (2013) Brazilian guidelines for the management of candidiasis - a joint meeting report of three medical societies: Sociedade Brasileira de Infectologia, Sociedade Paulista de Infectologia and Sociedade Brasileira de Medicina Tropical. Braz J Infect Dis 17:283-312.

Colombo AL, Garnica M, Camargo LFA, Cunha CA, Bandeira AC, Borgui D, Campos T, Senna AL, Bidier MEV, Dias VC (2013) Candida glabrata: an emerging pathogen in Brazilian tertiary care hospitals. Med Mycol 51:38-44.

Cruz MC, Goldstein AL, Blankenship JR, Del Poeta M, Davis D, Cardenas ME, Perfect JR, McCusker JH, Heitman J (2002) Calcineurin isessential for survival during membrane stress in Candida albicans. EMBO J 21:546-559.

Fekete-Forgacs K, Gyure L, Lenkey B (2000) Changes of virulence factors accompanying the phenomenon of induced fluconazole resistance in Candida albicans. Mycoses 43:273-279.

Hull CM, Bader O, Parker JE, Weig M, Gross U, Warrilow AG, Kelly DE, Kelly SL (2012) Two clinical isolates of Candida glabrata exhibiting reduced sensitivity to amphotericin B both harbor mutations in ERG2. Antimicrob Agents Chemother 56:6417-6421.

Johnson MD, MacDougall C, Ostrosky-Zeichner L, Perfect JR, Rex JH (2004) Combination antifungal therapy. Antimicrob Agents Chemother 48:693-715.

Mukherjee PK, Sheehan DJ, Hitchcock CA, Ghannoum MA (2005) Combination treatment of invasive fungal infections. Clin Microbiol Rev 18:163 194.

Niimi K, Woods MA, Maki K, Nakayama H, Hatakenaka K, Chibana H, Ikeda F, Ueno K, Niimi M, Cannon RD, Monk $\mathrm{BC}$ (2012) Reconstitution of high-level micafungin resistance detected in a clinical isolate of Candida glabrata identifies functional homozygosity in glucan synthase gene expression. J Antimicrob Chemother 67:1666-1676.

Onyewu C, Blankenship JR, Del Poeta M, Heitman J (2003) Ergosterol biosynthesis inhibitors become fungicidal when combined with calcineurina inhibitors against Candida albicans, Candida glabrata, and Candida krusei. Antimicrob Agents Chemother 47:956-964.

Pappas PG, Kauffamn CA, Andes D, Benjamin Jr DK, Calandra TF, Edwards Jr JE, Filler SG, Fisher JF, Kullberg B, Ostrosky-Zeichner L, Reboli AC, Rex JH, Walsh TJ, Sobel JD (2009) Clinical Practice Guidelines for the Management of Candidiasis: 2009 Update by the Infectious Diseases Society of America. Clin Infect Dis 48:503-535.

Pasqualotto AC, Zimerman RA, Alves SH, Aquino VR, Branco D, Wiltgen D, do Amaral A, Cechinel R, Colares S, da Rocha IG, Severo LC, Sukiennik TCT (2008) Take control over your fluconazole prescriptions: The growing importance of Candida glabrata as an agent of candidemia in Brazil. Infect. Control Hosp Epidemiol 29:898-899. 
Pfaller MA, Diekema DJ (2007) Epidemiology of invasive candidiasis: A persistent public health problem. Clin Microbiol Rev 20:133-163.

Pfaller MA, Castanheira M, Lockhart SR, Ahlquist AM, Messer SA, Jones RN (2012) Frequency of decreased susceptibility and resistance to echinocandins among fluconazole-resistant bloodstream isolates of Candida glabrata. J Clin Microbiol 50:1199-1203.

Singh N (2003) Fungal infections in the recipients of solid organ transplantation. Infect Dis Clin North Am 17:113-134.
Steinbach WJ, Schell WA, Blankenship JR, Onyewu C, Heitman J, Perfect JR (2004) In vitro interactions between antifungals and immunosuppressants against Aspergillus fumigatus. Antimicrob Agents Chemother 48:1664-1669.

Sun S, Li Y, Guo QJ, Shi CW, Yu JL, Ma L (2008) In vitro interactions between tacrolimus and Azoles against Candida albicans determined by different methods. Antimicrob Agents Chemother 52:409-417.

Associate Editor: Carlos Pelleschi Taborda

All the content of the journal, except where otherwise noted, is licensed under a Creative Commons License CC BY-NC. 